\title{
A Commentary: Breathing Together Now
}

\author{
TIMOTHY K. CHOY \\ UNIVERSITY OF CALIFORNIA, DAVIS
}

It is a challenging and important time to breathe together. This is not to suggest a unifying characterization of a contemporary moment. I call it a challenging time, in fact, precisely because the moment and place in which I am encountering this collection roars with so many multiple, overlapping, resonating, and yet incommensurate callings-out of respiratory distress and systemic breathing disorderings, as well as agitations for somethings-else.

To name a few: I am writing in the middle of the COVID-19 pandemic, whose main medium of transmission is likely aerosols expelled as breath, making the possibilities of sharing air with others a pointed matter whether one longs for proximity in the slogs of social distance or avoids it for fear of contagion. I am also writing in the middle of a devastating season of wildfires in California that have already burned over 4 million acres and smoked the skies into new hues. I work from home, shelter from smoke, and scan fire alerts in a house for which I hold a title on unceded Ohlone land, the deed for which contains an unenforceable yet still arresting racially restrictive covenant stipulating, "No lot nor plot nor building in tract shall be occupied nor resided upon by persons not wholly of the white Caucasian Race except servants or domestics employed by...a white Caucasian owner or tenant." I write in the long middle of antiBlack violence in the United States, in the time of George Floyd's choking at the knee of Minneapolis police, and movements for Black lives against the repetition of Black breathing denied. Breath is heavy here, its weight palpable and disorienting in recent and ongoing marches where protestors wear masks to protect selves and others from possible COVID contagion, while also citing Floyd's last words, "I can't breathe," themselves an uncanny citation of Eric Garner's words when he was killed in a NYPD chokehold in 2014, as well as Frantz Fanon's rendering of Black living as an ongoing pulse of combat breathing. A transpersonal gestural enactment of momentarily shared pandemic respiratory thickening paired incommensurably yet viscerally with linguistic and textual repetitions of racialized respiratory violence. Meanwhile, tear gas deployed by police against Black Lives Matter protestors in US cities recalls the ground level chemical clouds mobilized against pro-democracy demonstrators in Hong Kong, residents and protestors in Kashmir, water protectors at Standing Rock, and countless other mobilizations-a continuity of crowd control weaponry that has conditioned new crowds and forms for solidarity among the gassed via exchanges of defensive techniques against atmospheric assault.

Here and now, as I write, breathing conditions, air restrictions, and air flows have become highly explicit objects of attunement, concern, and care. Breathing and breath have

'Timothy K. Choy, Email: tkchoy@ucdavis.edu

Copyright (C) 2020 (Timothy K. Choy). Licensed under the Creative Commons Attribution Non-commercial No Derivatives (by-nc-nd). Available at estsjournal.org. 
become an increasingly durable, if pliable, problem-space (Ahmann, this collection) for naming political problems and doing political work. So, too, have devices-technological, representational, aesthetic, experimental--proliferated in projects for sensing, documenting, infrastructuring (Kenner, this collection), and triangulating (Grandia, this collection) for an exit to toxic conditions. In these middles, universality, connection, and common exposure and vulnerability are consubstantial with stratification, sacrifice, and unequal distribution.

This wideness opens as an arena of breathers. And part of the work of drawing breath together entails the proliferation of respiratory comparisons, contrasts, and connections. If those I have mentioned press me immediately, still others surround me, bringing and layering in their own temporal and spatial distributions and scalings. The wildfires that preoccupy me today in California followed a devastating season of bushfires in Australia that burned through 46 million acres, killed billions of non-human animals, and pushed a $1000 \mathrm{~km}$-wide smoke cloud into the stratosphere. Alongside the current urgency and mobilization of resources for COVID-19 responses, consider the slow trickle of funding for vaccine development for tuberculosis, the leading infectious cause of death worldwide. Surveying the roughly 10 million reported cases of TB worldwide from 2019, the WHO's 2020 Global Tuberculosis Report reports that roughly 1.4 million people died of TB last year, and that the global tuberculosis epidemic continues to distribute itself unequally, causing greater rates of mortality in developing countries, as well as in poor communities and in prisons in wealthier countries (Global Tuberculosis Report 2020). TB advocates in South Africa point out that the number of people who died of tuberculosis last year $(58,000)$ is more than double the number of South Africans who have died of COVID-19. Meanwhile, the number of reported COVID-19 cases in India, second only to that of the US, prompts Indian journalists and doctors to ask what effect a confluence of respiratory burdens will bring as the fall "pollution season" in New Delhi-an effect of temperature and wind patterns combined with seasonal agricultural burning in the region-has brought PM2.5 levels into the 180-300 microgram $/ \mathrm{m}^{3}$ range (Dasgupta 2020). Recently, COVID-19 has also served as a prompt for philosopher Achille Mbembe to meditate on death, togetherness, and the ineluctable binds holding humanity, bodies, and biosphere together, proposing a "universal right to breath," where breath is "both ungrounded and our common ground," against modernity's "interminable war on life" (Mbembe 2020). While Mbembe's concerns implicate the constitutive violences of extractive economies in Africa supplying "resources and energy necessary for the global computing infrastructure," his broader call binds to and is formed by an address of shared respiratory vulnerability and ontological porosity made available and tender in a time of pandemic.

This is a lot. I gesture to some of the plenitude, while knowing and worrying over how much more there is, in order to mark two things. The first is that this thematic collection on "Breathing Late Industrialism" comes to us at a time when airs and breaths-and claims through them-are accumulating and aggregating across domains previously made separate (Grant, this collection). Gathering respiratory publics in new formations (Nguyen, this collection), atmospheric coalitions coalesce both through the affordances of the air as medium (Ahmann, this collection), and the pliability of and capaciousness of breath as a necessary and ongoing metabolic relation whose interruption makes breathers, breaths, and their conditions, explicit and 
available. Breathing is at once corporeal and meaningful, routine and affecting; it glides between measure and evocation.

This last point makes breath hard to follow in its ubiquities, which is related to the second part of what I said at the outset: that this is a challenging time to breathe together. For if there is contiguity by medium established in the varied engagements with breath, it's also true that they are profoundly about different matters. They are irreducibly different, sometimes incommensurable-and what is at stake in the reconciliations of atmospheric ledgers is often precisely the remainder. This creates some challenges: how to track and work with the suppleness of breathing as an organizing concept, while also binding particular moments and forms of respiratory attention and reckoning to the conditions that they emerge in and respond to.

The papers in this thematic collection show us ways to respond to this challenge. Together, they show how STS work invested in atmospheres, the propensities of materials and mediums, and the qualities of objects and relations can become more material, more nuanced, and more engaged and engaging, when we remember that atmospheric qualities and the terms of their description, relation, and abstraction, are neither given nor transcendent-they transpire in and of particular worlds. In the course of taking breath as a grounding object to gain traction on the binds and openings of late industrialism, the authors craft analytics grounded within the specificities of their locations that can also press on what attaches to breathing for another.

Tracking the emergence of "respiratory publics" in Beijing through everyday practices, Victoria Nguyen gathers uneventful moments such as the folding of a facemask for later use, people's enjoyment of underground spaces for recreation, and the posting and reposting of images of Beijing's air on WeChat and Weibo, which aggregate as a local atmospheric portrait. Aggregation takes on a different significance in Sonia Grant's paper, as Diné residents in the Greater Chaco not only argue for the aggregation of point sources, but also layer repeated accounts of smells, lost breath, heavy traffic, and unrecordable significances of the landscape into regulatory arenas where they are not legible as environmental impact. These aggregating tactics, we learn, respond not simply the capacities of airborne chemicals to accumulate, but also, critically, the disaggregating formats of settler governance in the Greater Chaco, including a checkerboard of jurisdictions and domainings severing air from land. Jurisdictions figure centrally in Chloe Ahmann's story as well, as she shows how participants in an anti-incinerator coalition in South Baltimore used the affordances of air to shift how bodily vulnerability and political authority are apportioned in response to fixed jurisdictional boundaries as well as to insider/outsider boundaries established as white landedness. Liza Grandia's contribution, meanwhile, casts the shifting potential of atmospheric problem-spaces in a different light, particularly in her discussion of a schoolboard's use of the presence of outdoor wildfire smoke to cast doubt on the validity of mothers' concerns about the effects of off-gassing carpets on indoor air quality in an elementary school in California's Central Valley as they attributed children's illnesses to the larger atmospheric envelope rather than enclosed interior air spaces. Ali Kenner follows the social and regulatory life of a different kind of smoke; she guides our attention from burning tires and garbage to the history of scrapyards in Philadelphia's Overton neighborhood 
through residents' complaints and sensory experiences of them, and into the category structures of a digital governance platform that provides no way for community members to report smoke, fires, and other environmental hazards. Finally, Alex Zahara begins his piece with lungs itchy from wildfire smoke, but pivots from there to an analysis of the naturalized "settler fire regime" of fire reintegration in Saskatchewan, only to return later to his noticing of breath as a prompt to reflect on the non-negotiable impurity of decisions made in compromised conditions, whether for finding better breathing conditions, or for Indigenous-led fire management.

Emerging in the thick of this challenging time for breathing together, even if conceived before, this collection speaks to, echoes, and offers traction for grasping something in the air-if not a "moment," then a becoming-coincident of situations and formations that share a partial connection through a medium-in-the-making. This is so even as (or perhaps precisely because) each author situates their work and their interventions so carefully in the specific conditions, communities, and situations that they are engaging. Read on their own terms as well as within earshot and airspace of other gasps and other activations, these papers teach us ways to study and to learn from existing efforts to make breathing room and alter-possibilities within existing infrastructures, jurisdictions, and socialities that touch bodies, lungs, and lands. They teach us how people "creatively retrofit" the infrastructures of late industrialism to facilitate projects to render and intervene in its spatially and temporally displaced effects; in doing so, the authors also retrofit existing fields of study so that they can be pressed into the work of new kinds of reckoning. Reckoning not with a generalized consubstantiation, but with the working out of particular tools-in practice, in analysis, in concept-making, in habits of description-for holding things in suspensive tension.

"It seems we have some catching up to do," Ahmann and Kenner remark in their introduction. The papers in this collection do this and more. They provide tools for orienting to what is emerging in and against late industrial conditions, and also for keeping pace and moving with the ever-shifting mix of conspirings and respiratory reckonings that are resounding in the present.

\section{Author Biography}

Tim Choy is an Associate Professor of Science and Technology Studies and an Associate Professor of Anthropology at the University of California, Davis. His interests include ecological discourses and practices, emergent politics of air and breath, questions of form, and collaboration. He is the author of Ecologies of Comparison: An Ethnography of Endangerment in Hong Kong, which won the Rachel Carson Prize from the Society for Social Studies of Science.

\section{References}

Ahmann, Chloe and Alison Kenner. 2020. "Breathing Late Industrialism." Engaging Science, Technology, and Society 6:416-438. 
Ahmann, Chloe. 2020. "Atmospheric Coalitions: Shifting the Middle in Late Industrial Baltimore." Engaging Science, Technology, and Society 6:462-485.

Dasgupta, Sravasti (2020). "Doctors Warn of Delhi Covid Spike as Pollution Levels Rise \& Temperature Begins to Drop." ThePrint (blog), October 15. https: / / theprint.in/ health/ doctors-warn-of-delhi-covid-spike-as-pollution-levels-risetemperature-begins-to-drop/523721/.

Global Tuberculosis Report 2020. Geneva: World Health Organization.

Grandia, Liza. 2020. "Toxic Gaslighting: On the Ins and Outs of Pollution." Engaging Science, Technology, and Society 6:486-513.

Grant, Sonia. 2020. "Aggregate Airs: Atmospheres of Oil and Gas in the Greater Chaco." Engaging Science, Technology, and Society 6:534-554.

Kenner, Alison. 2020. "Scrapping the Workshop of the World: Civic Infrastructuring and the Politics of Late Industrial Governance." Engaging Science, Technology, and Society 6:514533.

Mbembe, Achille (2020). "The Universal Right to Breathe." In the Moment (Critical Inquiry blog).

April 13. https: / / critinq.word press.com/2020/04/13/the-universal-right-to-breathe/.

Nguyen, Victoria. 2020. "Breathless in Beijing: Aerial Attunements and China's New Respiratory Publics." Engaging Science, Technology, and Society 6:439-461.

Zahara, Alex. 2020. "Breathing Fire into Landscapes that Burn: Wildfire Management in a Time of Alterlife." Engaging Science, Technology, and Society 6:555-585. 